\title{
SOBRE LA MODERNIZACIÓN DEL LENGUAJE JURÍDICO: UNA MIRADA EN ESPAÑA E ITALIA
}

\author{
ABOUT THE MODERNISATION OF LEGAL LANGUAGE: \\ A LOOK AT SPAIN AND ITALY
}

\author{
RubÉn GonZÁlez VALlejo \\ Università degli Studi di Macerata, Italia \\ r.gonzalezvallejo@unimc.it \\ https://orcid.org/0000-0002-9697-6942
}

\section{Resumen}

El presente artículo nace a raíz de la decisión de retomar la simplificación de los textos oficiales por parte de la Comisión para la modernización del lenguaje jurídico en el mes de junio de 2020. Dicho informe nació de la Carta de los Derechos de los Ciudadanos ante la Justicia en abril de 2002 y reúne las principales consideraciones para una mayor comprensión del lenguaje de las leyes. A tal propósito, se mostrará un breve recorrido por los esfuerzos de simplificación del lenguaje más destacados en España e Italia. Posteriormente, se detallarán las principales recomendaciones del Informe de la Comisión de modernización del lenguaje jurídico para el caso español y del manual Regole

\begin{abstract}
This article follows the decision to take up the simplification of official texts by the Commission for the modernisation of legal language in June 2020. It follows on from the Charter of Citizens' Rights in April 2002 and brings together the main considerations for a better understanding of the language of laws. In this regard, a brief overview of the most important language simplification efforts in Spain and Italy will be provided. Subsequently, the main recommendations of the Report of the Commission for the modernisation of legal language for the Spanish case and the manual Regole e suggerimenti per la redazione dei testi normativi for the Italian case will be detailed, with the aim of presenting a reflection on the efforts of both countries
\end{abstract}

Para citar este artículo González Vallejo, Rubén (2021). Sobre la modernización del lenguaje jurídico: una mirada en España e Italia. ELUA, 35: 109-123. https://doi.org/10.14198/ELUA2021.35.6

Recibido: 15/07/2020, Aceptado: 18/12/2020

C) 2021 Rubén González Vallejo 
e suggerimenti per la redazione dei testi normativi para el caso italiano, con el objetivo de exponer una reflexión acerca del esfuerzo de ambos países a través de numerosos ejemplos legislativos extraídos de la base de datos del BOE y de Normattiva.

PALABRAS CLAVE: lenguaje jurídico; modernización del lenguaje; derecho; simplificación; normativa. through numerous legislative examples extracted from the BOE and Normattiva databases.

KEYWORDS: legal language; modernization of language; law; simplification; regulation.

\section{INTRODUCCIÓN}

El derecho es producto de los grupos sociales que operan en una sociedad, tiene el propósito prescriptivo de regular el comportamiento en ella y de recoger diacrónicamente sus fenómenos sociales. Los cambios en la sociedad inciden en el derecho a través de las normas, pues de las mismas dependerá la efectividad del orden en la comunidad. Estas comunidades se encuadran en sistemas jurídicos, caracterizados fuertemente por los rasgos socioculturales de las fuentes que subyacen en su creación. En el caso del derecho romano-germánico, la familia jurídica a la que pertenece el ordenamiento italiano y español, la fidelidad a la costumbre y a la carta magna se ha plasmado a través de un lenguaje grandilocuente. Esto es debido a que el lenguaje jurídico es una variedad de la lengua común caracterizada culturalmente por todos los preceptos que deben seguir los participantes desde una óptica abstracta y abstrusa, con el fin de aplicarse con carácter atemporal en las normas jurídicas.

El lenguaje jurídico varía de sociedad a sociedad, pues dentro de cada ordenamiento los fenómenos sociales han dado lugar a conceptos terminológicos distintos, incluso entre países que hablan el mismo idioma (nótese el caso de los países que engloba el gran espectro de Hispanoamérica). Esto propicia una especialidad basada en los anisomorfismos socioculturales y en la ansiada búsqueda de la equivalencia funcional entre los distintos ordenamientos. En el caso español e italiano, el lenguaje jurídico se ha puesto de manifiesto usualmente por sus usos repetitivos, arcaizantes y por su oscurantismo (Gotti 1991; Alcaraz y Hughes 2002), lo cual ha impulsado una preocupación constante por la modernización del lenguaje jurídico, pues como bien se indica ya en el art. 117 de la Constitución española (CE), "la justicia emana del pueblo", con lo cual, quien la origina, la debe comprender.

Si bien numerosos han sido los estudios dedicados al lenguaje jurídico precisamente por la necesidad de comprensión que debieran desprender las normas jurídicas (Gozzi 2004), menos han sido los informes y las comisiones creadas para su simplificación en el caso italiano. Desde hace años el lenguaje jurídico presencia movimientos e iniciativas para modernizar su lenguaje con el objetivo de que pueda adaptarse tanto a nivel lingüístico, mediante la elusión de aquellas formas del español en desuso por la mayor parte de la población, como socialmente a través de un medio de expresión cercano al ciudadano. La preocupación por adaptar este lenguaje de especialidad no pertenece únicamente a España, donde se eliminaron las fórmulas de saludo y despedida como "que Dios guarde" (q. D. g) y en la que se ha podido constatar un auge en la creación de manuales de estilo, como el Libro de Estilo del Ilustre Colegio de Abogados de Madrid (2007) publicado por Fundéu o el Manual de estilo del lenguaje administrativo (1990) publicado por el Instituto Nacional de Administración 
Pública, entre otros ${ }^{1}$. El debate italiano acerca de la simplificación del lenguaje jurídico, por su parte, ya abrió sus puertas a finales de los años 80 con el propósito de reescribir las leyes, lo cual vio florecer diversos manuales en aras de modernizar el lenguaje jurídico, siendo el manual de Cassese en 1993 el punto de referencia principal en la redacción legislativa.

Etxebarria (1997) menciona el Plain English Campaign que se llevó a cabo en Inglaterra en 1979 con el objetivo de evitar el lenguaje abstruso legal. En EE. UU, en cambio, una comisión de lingüistas empezó a trabajar en 1975 con el fin de reproducir textos intricados de manera inteligible. En Francia y en Canadá apostaron por el campo terminológico mediante la creación del Alto Comité de la Lengua Francesa fundado en 1983, cuya función es la de promover la creatividad lingüística para evitar la entrada de términos técnicos ajenos y "establecer vocabularios terminológicos y proponer la definición y adopción de términos" (Etxebarria 1997: 369). Suecia, a su vez, demostró una gran diligencia en la simplificación del lenguaje jurídico al disponer de comisiones de expertos que revisan los documentos enviados al Parlamento y al crear planes de acción para llevarlos a cabo en las instituciones públicas.

A continuación, se procurará una mirada en España e Italia sobre la modernización del lenguaje jurídico como necesidad imperante de presentar con una visión actual un lenguaje que conserva rasgos inmutables, y en ocasiones accesorios, y que se sitúa en el punto de mira por representar un escollo en la redacción legislativa.

\section{EL CASO ESPAÑOL}

En España, la inquietud por la simplificación del lenguaje surgió tímidamente en 1958 con una Orden presidencial que eliminaba las fórmulas de saludo y despedida. Años más tarde, en 1986, una Orden Ministerial estableció algunas reglas claras para la redacción de textos oficiales (Relinque Barraca 2017). Sin embargo, los intentos de modernizar el lenguaje jurídico llegaron más tarde con respecto al panorama internacional, de la mano de la democracia, creando el Manual de Estilo del lenguaje Administrativo (1990). Sin embargo, la gran renovación lingüística no llegó hasta 2002 con la Carta de derechos del ciudadano ante la Justicia (Montolío Durán 2013). Esta carta fue impulsada por el Congreso, con el objetivo de confeccionar una lista de derechos de los ciudadanos ante la ley. Dividida en 4 capítulos y bajo 44 principios, se encuentran afirmaciones que muestran la propensión a simplificar el lenguaje jurídico, como el principio 5, "El ciudadano tiene derecho a que las notificaciones, citaciones, emplazamientos y requerimientos contengan términos sencillos y comprensibles, evitándose el uso de elementos intimidatorios innecesarios"; el 6, "El ciudadano tiene derecho a que en las vistas y comparecencias se utilice un lenguaje que, respetando las exigencias técnicas necesarias, resulte comprensible para los ciudadanos que no sean especialistas en derecho" y el principio 7, "El ciudadano tiene derecho a que las sentencias y demás resoluciones judiciales se redacten de tal forma que sean comprensibles por sus destinatarios, empleando una sintaxis y estructura sencillas, sin perjuicio de su rigor técnico".

Un año más tarde, en 2003, se creó la Comisión para la Modernización del Lenguaje Jurídico con la Orden JUS/3126/2003, compuesta por profesionales del ámbito jurídico y

1 En conformidad con lo expuesto por autores como Etxebarria (1997) y González Salgado (2009), la diferencia entre el lenguaje jurídico y el administrativo no es nítida y se adoptarán ambos como un único lenguaje, a sabiendas de que el lenguaje administrativo es el utilizado en lo relativo a la Administración y el lenguaje jurídico es el empleado en textos de leyes y por profesionales de la jurisdicción (González Salgado 2009: 236-237). 
lingüístico con el objetivo de elaborar un informe acerca de la situación y de las modificaciones pertinentes para favorecer el acceso de las personas a las normas de la comunidad. Posteriormente, en 2005, salió la aprobación del Plan de Transparencia Judicial, que en su apartado VII, bajo el título modernización del lenguaje jurídico, recogió la necesidad de realizar un lenguaje jurídico comprensible enlazándose tanto a la Carta de 2002 como a la Comisión creada en 2003. En 2008, en cambio, se aprobó el Plan de Modernización de la Justicia con el objetivo de llevar a cabo lo redactado en la Carta de Derechos y en el Plan de Transparencia Judicial. Por último, tras la colaboración entre la Real Academia Española y el Consejo General del Poder Judicial, se presentó en el año 2017 El libro de estilo de la Justicia, con el fin de esclarecer ulteriormente aún más el oscurantismo del lenguaje jurídico.

A continuación, y digno de atención, se analizará el Informe de la Comisión de modernización del lenguaje jurídico publicado por el Ministerio de Justicia en 2011, en donde se recogen diversas recomendaciones dirigidas tanto a las instituciones como a los profesiona$\operatorname{les}^{2}$. Para ello, se mostrará un listado de las pautas más notables del susodicho informe junto con algunos ejemplos inadecuados extraídos de la legislación del BOE (1) y una propuesta de mejora para una eficaz redacción del lenguaje legislativo (2). Los elementos susceptibles de modificación del fragmento original se evidenciarán mediante la técnica del subrayado, mientras que su correspondencia en el texto adaptado se resaltará en cursiva siempre que no hayan sido omitidos por motivos estilísticos:

Los mecanismos expresivos, así como las características de cada texto, constituirán la base coherente sobre la cual se erigirá el discurso. Este será ordenado y preciso en función de los razonamientos exigidos por la argumentación. En los textos descriptivos impera el orden, tanto espacial como de importancia o tamaño y el léxico apropiado para delimitar el concepto. En el discurso narrativo, en cambio, será necesaria la precisión de los sujetos que componen la escena y de los eventos acaecidos. Por último, en el discurso argumentativo, cuyo objetivo latente es el de convencer, la explicitación mediante un lenguaje fluido y la correcta distinción entre la argumentación escrita y oral permitirá diferenciar los argumentos de las conclusiones. A tal propósito, se antoja imprescindible la eficaz ordenación de los párrafos para delimitar correctamente las unidades temáticas del texto y el papel de los marcadores discursivos, vista la necesidad de coherencia entre las partes de un mismo párrafo o entre dos contiguos. Estos no deben estar compuestos por una sola oración y se deberá evitar el uso de las repeticiones a través de deícticos en párrafos extensos.

(1) Si la prueba solicitada fuera la pericial médica sobre la imputabilidad del inculpado, el Instructor podrá acordar el internamiento de éste en un establecimiento sanitario militar y designará a un facultativo del mismo para que proceda, por el plazo mínimo necesario, que no podrá exceder de diez días, al estudio y reconocimiento de aquél, limitándose en este momento la práctica de dicha prueba a la preparación de la misma, a fin de que las

2 El Informe de la Comisión sobre el lenguaje jurídico se basa en una estrecha colaboración con el CGPJ, con el Consejo General de la Abogacía Española y con diversos colaboradores y expertos consultados. Los principales estudios de campo que subyacen son los siguientes: el Informe sobre lenguaje oral, dirigido por Antonio Briz Gómez (Universidad de Valencia); el Informe sobre lenguaje escrito, dirigido por Estrella Montolío Durán (Universidad de Barcelona); el Informe sobre plantillas procesales, dirigido por Julio Borrego Nieto (Universidad de Salamanca); el Informe sobre lenguaje de las normas, dirigido por Salvador Gutiérrez Ordóñez; el Informe sobre políticas públicas comparadas, dirigido por Cristina Carretero González (Universidad Pontificia de Comillas) y el Informe sobre lenguaje jurídico en los medios, dirigido por María Peral Parrado. 
conclusiones del reconocimiento del inculpado puedan ser puestas de manifiesto por el perito susodicho en el acto de la vista. (Art. 391, Ley Orgánica 2/1989)

(2) Si la prueba solicitada fuera la pericial médica sobre la imputabilidad del inculpado, el Instructor podrá acordar el internamiento de este en un establecimiento sanitario militar y designará a un facultativo para que proceda, por el plazo mínimo necesario, que no podrá exceder de diez días, al estudio y reconocimiento de aquel, limitándose en este momento la práctica de dicha prueba a su preparación. Todo ello con el fin de que las conclusiones del reconocimiento del inculpado puedan ser puestas de manifiesto por el perito en el acto de la vista.

Las oraciones presentes en el lenguaje jurídico se caracterizan por su excesiva complejidad y subordinación. En las oraciones se puede observar un uso recurrente de la oración pasiva, del gerundio, de la preposición $a$, del futuro del subjuntivo y de las mayúsculas, entre otros. Por ello, para una mayor comprensión, se recomienda realizar un uso diligente de los signos ortográficos, especialmente la coma y el punto y coma, y evitar la concatenación excesiva de frases subordinadas. En el siguiente ejemplo, carente de comas, se abre las puertas al anacoluto.

(1) Según los artículos 7 de la Ley de Fundaciones, el 4 del Reglamento de fundaciones de competencia estatal y el 24. J del Real Decreto 1611/2007, de 7 de diciembre, por el que se aprueba el Reglamento del Registro de fundaciones de competencia estatal, la inscripción de las delegaciones de las Fundaciones extranjeras requerirá el informe favorable del Protectorado en cuanto a la idoneidad de los fines de la fundación matriz son de interés general con arreglo al ordenamiento jurídico español, así como la aportación del primer plan de actuación de la Delegación, constando en el expediente informe favorable del Protectorado de Fundaciones de fecha 9 de julio de 2019. (Resolución de 20 de enero de 2020)

(2) Según los artículos 7 de la Ley de Fundaciones, el 4 del Reglamento de fundaciones de competencia estatal y el 24. J del Real Decreto $1611 / 2007$, de 7 de diciembre, por el que se aprueba el Reglamento del Registro de fundaciones de competencia estatal, la inscripción de las delegaciones de las Fundaciones extranjeras requerirá el informe favorable del Protectorado en cuanto a la idoneidad de los fines de la fundación matriz. Son de interés general con arreglo al ordenamiento jurídico español, así como la aportación del primer plan de actuación de la Delegación, constando en el expediente informe favorable del Protectorado de Fundaciones de fecha 9 de julio de 2019.

La oración pasiva designa lejanía entre el ciudadano y las leyes, por ello se desaconseja su uso si no es estrictamente necesario (sobre todo si con la pasiva refleja se usa el complemento agente, tan usado en los textos jurídicos). El gerundio, por su parte, normalmente da lugar a construcciones agramaticales por lo que se recomienda un uso limitado y correcto (el gerundio especificativo tiene correspondencia en una oración de relativo mientras que el gerundio de posterioridad en una oración coordinada).

(1) En el caso de que un Tribunal sin causa legítima debidamente justificada, se hubiese extralimitado de los términos establecidos en el presente título para la sustanciación y decisión de las competencias, será corregido prudencial y disciplinariamente según la gravedad del caso. (Art. 44, Real Decreto 1982). 
(2) En el caso de que un Tribunal sin causa legítima debidamente justificada, se hubiese extralimitado de los términos establecidos en el presente título para la sustanciación y decisión de las competencias, se corregirá prudencial y disciplinariamente según la gravedad del caso.

(1) Ser Jefe inmediato y principal responsable de los trabajos de oficina, y cuidar de que todos los asientos, libros y documentos se encuentren al día y en completa regularidad, debiendo revisar mensualmente los libros de la Oficina, haciendo constar el resultado mediante nota autorizada. (Art. 22. 4, Decreto 1947)

(2) Ser Jefe inmediato y principal responsable de los trabajos de oficina, y cuidar de que todos los asientos, libros y documentos se encuentren al día y en completa regularidad, además de deber revisar mensualmente los libros de la Oficina $y$ de hacer constar el resultado mediante nota autorizada.

La preposición $a$ constituye un error frecuente al ser usada como su análoga francesa, ya que hay construcciones en las que se recomienda evitarla y usar en su lugar "para" o "a fin de", como en el ejemplo "asuntos para tratar" en lugar de "asuntos a tratar". Por otra parte, la no repetición del artículo en todos los elementos de una frase representa otro problema, como en el caso de "las nuevas modificaciones no solo afectarán a la estructura de las sociedades, sino también a la defensa, derechos y jornada de los trabajadores" en lugar de "las nuevas modificaciones no solo afectarán a la estructura de las sociedades, sino también a la defensa, a los derechos y a la jornada de los trabajadores".

(1) El Presidente designará un ponente para cada asunto a tratar, que informará a la Sala y presentará [...]. (Art. 55, Ley Orgánica 6/1985)

(2) El Presidente designará un ponente para cada asunto para tratar, que informará a la Sala y presentará $[\ldots]$.

En cuanto al subjuntivo, se recomienda que el futuro de subjuntivo se sustituya por el pretérito perfecto o imperfecto de subjuntivo.

(1) En los delitos y faltas que se cometan utilizando medios o soportes de difusión mecánicos no responderán criminalmente ni los cómplices ni quienes los hubieren favorecido personal o realmente. (Art. 30.1, Ley Orgánica 10/1995)

(2) En los delitos y faltas que se cometan utilizando medios o soportes de difusión mecánicos no responderán criminalmente ni los cómplices ni quienes los hayan favorecido personal o realmente.

Por otra parte, se deberá tener en cuenta el empleo incorrecto de las mayúsculas que se utilizan para designar organismos genéricos y no propios, como en el siguiente ejemplo, en el que se hace un uso incoherente de las mismas:

(1) (...) interviniendo un Órgano de CAJA MADRID incompetente para ello, y OBVIANDO EL CONTROL DE LA CONSERJERÍA DE ECONOMÍA Y HACIENDA, exigido por el art. 56.1. (P.A 3173/ 2013) 
(2) (...) interviniendo un Órgano de Caja Madrid incompetente para ello, y obviando el control de la Conserjería de Economía y Hacienda, exigido por el art. 56.1.

En cuanto a la terminología, la Comisión de modernización del lenguaje jurídico se opone firmemente al uso del vocabulario abstruso del que hacen uso algunos profesionales del sector por considerarlo indispensable e inherente al lenguaje jurídico. Por ello, recomiendan que los arcaísmos y las locuciones latinas se sustituyan por un lenguaje más llano y que se expliquen los tecnicismos en la medida de lo posible.

(1) [...] dado que la derogación, con sus efectos ex nunc, no es equivalente a una hipotética declaración de nulidad [...]. (STC 117/2011)

(2) [...] dado que la derogación, con sus efectos a partir de ahora, no es equivalente a una hipotética declaración de nulidad, [...].

En cuanto a las citas, se recomienda evitar un uso continuado de las mismas debido a que pueden dificultar la comprensión del texto. En el caso del uso de una cita, tendrá que estar correctamente delimitada por comillas españolas ( \langle\rangle$)$ o inglesas (“"), y si ya dispone de palabras delimitadas por estas últimas, se recurrirá a las simples ("). No obstante, la predilección por el uso de las angulares en primera instancia en diferentes manuales (RAE 2005; Tribunal Supremo 2016), lleva irremisiblemente a la modificación de esta recomendación:

(1) "Dada una oportunidad, la misma se aprovechó exitosamente durante seis años", recuerda su recurso, que reflexiona así sobre su hipotética reincorporación a la sociedad: Antonio ve denegados sus permisos de salida porque "el riesgo actual de reincidencia es elevado" dada su "dilatada e intensa trayectoria delictiva". El fiscal recoge en su informe de febrero que el interno ha cometido durante su vida numerosos robos con violencia, con tenencia ilícita de armas, lesiones, amenazas, que requieren "un mayor período efectivo" [...]. (Sentencia 6/2020)

(2) «Dada una oportunidad, la misma se aprovechó exitosamente durante seis años», recuerda su recurso, que reflexiona así sobre su hipotética reincorporación a la sociedad: Antonio ve denegados sus permisos de salida porque «el riesgo actual de reincidencia es elevado» dada su «dilatada e intensa trayectoria delictiva». El fiscal recoge en su informe de febrero que el interno ha cometido durante su vida numerosos robos con violencia, con tenencia ilícita de armas, lesiones, amenazas, que requieren «un mayor período efectivo» [...].

Por último, y por lo que concierne a las referencias, debido a la ambigüedad que suelen presentar deberán ser estructuradas en función de las normas bibliográficas. Asimismo, deberán contener en el caso de las referencias a la legislación, "rango normativo, número, denominación fiscal si la tienen, fecha y, entre paréntesis, publicación oficial con referencia de número y fecha" (p. 13).

(1) El Registrador de la Propiedad tramitará la correspondiente inscripción por el procedimiento establecido en el artículo 199.2 de la Ley Hipotecaria, y notificará a los titulares registrales y catastrales de las parcelas colindantes afectadas, [...]. (Resolución de 7 de octubre de 2020) 
(2) El Registrador de la Propiedad tramitará la correspondiente inscripción por el procedimiento establecido en el artículo 199.2 de la Ley Hipotecaria 13/2015, de 24 de junio (BOE núm. 151, de 25/06/2015), y notificará a los titulares registrales y catastrales de las parcelas colindantes afectadas, [...].

A continuación, en el siguiente epígrafe se detallarán los esfuerzos llevados a cabo en Italia para modernizar el lenguaje jurídico, junto con ejemplos extraídos del manual Regole e suggerimenti per la redazione dei testi normativi publicado en 1991 por el Osservatorio Legislativo Interregionale.

\section{EL CASO ITALIANO}

A finales de los años 80 empieza el debate sobre la simplificación del lenguaje jurídico a través del exitoso Rapporto sui principali problemi sulla Amministrazione dello Stato publicado en noviembre de 1979, el cual puso de manifiesto las preocupaciones primordiales sobre la mejora de las administraciones. Entre las cuestiones más notables, se encontraba el cargo dirigido a departamentos concretos para reescribir las leyes de manera inteligible.

Sin embargo, no será hasta el año 1993, en manos del Ministro Cassesse, cuando se realice el primer paso hacia la modernización del lenguaje a través del Codice di stile delle comunicazioni scritte ad uso delle amministrazioni pubbliche (Albano 2004), mediante la Ley 241/1990 de 7 de agosto que ya preveía los principios de "semplificazione, pubblicità e trasparenza dell'azione amministrativa" (Bombardelli 2008: 391). Se trata de un documento complejo compuesto por tres extensas partes que intenta recopilar las bases generales que debían adoptar los textos oficiales en su lenguaje. Ya en su preámbulo, el ministro Cassesse insistía en que "una pubblica amministrazione che sia realmente al servizio dei cittadini [...] deve garantire ai suoi utenti una comunicazione chiara e univoca" (Presidenza del Consiglio dei Ministri 1994: 11). El libro además recoge al final el Vocabolario di base di Tullio De Mauro, en donde se encuentran las siete mil palabras más usadas de la lengua italiana.

Posteriormente apareció en 1997 el llamado Manuale di stile editado por Alfredo Fioritto, como culminación del proyecto Semplificazione del linguaggio Amministrativo llevado a cabo por Cassesse. En relación con el Codice, se presenta como un manual más práctico "suddiviso in tre parti: una guida pratica alla costruzione testuale, sintattica e lessicale dei documenti; un glossario di base con le 500 parole di più comune uso amministrativo; una guida all'impaginazione dei documenti" (Pedone 2004: 991).

En febrero de 2002 el Dipartamento della Funzione Pubblica emanó una circular a favor de las relaciones con los ciudadanos titulada Attività di comunicazione delle pubbliche amministrazioni, que produjo meses más tarde la Direttiva sulla semplificazione del linguaggio dei testi amministrativi, concebida como una continuación de los dos manuales anteriores y dotada de un carácter más formal. Se divide en dos partes: en la primera se abordan las reglas de comunicación y estructura de los textos jurídicos, en donde se insiste en la claridad, en la lógica, en la importancia del destinatario, en la información completa y correcta, en la relectura de los textos y en el uso de notas y tablas para facilitar la lectura. En la segunda parte dedicada a la escritura, en cambio, se encuentra el tratamiento de los neologismos, las siglas y las mayúsculas; la preferencia por la redacción de frases breves; un uso menor de tecnicismos y un recurso predominante a las palabras provenientes del lenguaje común. 
Posteriormente, fruto adicional de esta normativa, aparece el proyecto Chiaro! creado por el mismo Departamento, con el fin de reunir los materiales necesarios en la página web del Ministero per la Pubblica Amministrazione para la adecuada redacción legislativa por parte de las administraciones públicas.

Por último, y digno de nota, se encuentra el manual Regole e suggerimenti per la redazione dei testi normativi publicado en 1991 por el Osservatorio Legislativo Interregionale ${ }^{3}$. Se trata de un manual que goza de tres ediciones, cuya última publicación salió a la luz en el año 2007. En esta versión se recoge meticulosamente un conjunto de normas sobre redacción legislativa con el objetivo de hacer que el lenguaje de la administración sea más claro. En él además se pone de manifiesto la necesidad de actualizar periódicamente el manual debido a la gran difusión que tiene tal lenguaje. Se divide en 5 capítulos que engloban el lenguaje jurídico a través de un análisis léxico-semántico del mismo, la estructura de los textos normativos, la estructura del acto reglamentario, la intertextualidad con las continuas referencias tanto internas como externas a otros textos de ley como protagonistas y las modificaciones.

Análogamente a lo realizado en el apartado anterior para el caso español, se extraerá de la base de datos Normattiva ejemplos incorrectos provenientes del lenguaje legislativo (1) para añadir posteriormente una propuesta de mejora (2). Siempre que sea posible por motivos de reformulación, los elementos susceptibles de modificación del fragmento original se evidenciarán mediante la técnica del subrayado, mientras que su correspondencia en el texto adaptado se resaltará en cursiva siempre que no hayan sido omitidos por motivos estilísticos. Algunas de las pautas que se pueden observar del manual italiano para redactar un texto oficial diligente son las siguientes:

Se recomienda la concisión de las frases, pues deberán ser breves y sin incisos, además de indicar la frase principal con anterioridad al elemento de subordinación.

(1) Lo straniero che, fuori dei casi indicati negli articoli 7 e 8 , commette in territorio estero, a danno dello Stato o di un cittadino, un delitto per il quale la legge italiana stabilisce l'ergastolo, o la reclusione non inferiore nel minimo a un anno, è punito secondo la legge medesima, sempre che si trovi nel territorio dello Stato, e vi sia richiesta del ministro di grazia e giustizia, ovvero istanza o querela della persona offesa. (Art. 10. 1. Codice Penale Italiano)

(2) Fuori dei casi indicati negli articoli 7 e 8 , lo straniero che commette in territorio estero un delitto per il quale la legge italiana stabilisce l'ergastolo o la reclusione non inferiore nel minimo a un anno, è punito secondo la legge medesima sempre che si trovi nel territorio dello Stato e vi sia richiesta del ministro di grazia e giustizia, ovvero istanza o querela della persona offesa.

(1) Il condannato alla reclusione per un tempo non inferiore a cinque anni è, durante la pena, in stato d'interdizione legale; la condanna produce altresì, durante la pena, la sospensione

3 Contrariamente al manual analizado para el caso español, el grupo de trabajo para la redacción normativa del manual Regole e suggerimenti per la redazione dei testi normativi no se basa en informes específicos emanados por equipos de investigación, sino que está elaborado por el Osservatorio legislativo interregionale y realizado por lingüistas y expertos del sector jurídico provenientes de diferentes centros de investigación, universidades y consejos regionales de la mayoría de las regiones italianas. 
dall'esercizio della responsabilità genitoriale, salvo che il giudice disponga altrimenti. (Art 32. 3 Codice Penale Italiano)

(2) Durante la pena, il condannato alla reclusione per un tempo non inferiore a cinque anni è in stato d'interdizione legale. Inoltre, la condanna produce durante la pena la sospensione dall'esercizio della responsabilità genitoriale, salvo che il giudice disponga altrimenti.

En cuanto al estilo, se prefiere la simplificación a la elegancia y a la grandilocuencia, las cuales tienden a usar adjetivos o adverbios que añaden ampulosidad y que carecen de contenido informacional.

1) La lavoratrice ha facoltà di usufruire delle prestazioni supplementari di giorni 15 precedentemente o susseguentemente al parto. (Reggio Decreto núm. 1641, 1942).

2) La lavoratrice ha facoltà di beneficiare delle prestazioni supplementari di giorni 15 prima o dopo al parto.

En el modo y los tiempos verbales, impera la regla de usar el indicativo para otorgar una homogeneización al texto. Únicamente se usarán otros modos ante la imposibilidad de usar el anterior.

(1) Nessuno può essere punito per un fatto che non sia espressamente preveduto come reato dalla legge, né con pene che non siano da essa stabilite. (Art. 1.1, Codice Penale Italiano)

(2) Nessuno può essere punito per un fatto che non è espressamente preveduto come reato dalla legge, né con pene che non sono state da essa stabilite.

Se prefiere evitar el uso de los verbos modales para favorecer el indicativo. Asimismo, se eludirá el uso de dovere y el verbo potere solo se usará para una capacidad y no para una obligación.

(1) h) le commissioni devono essere limitate al recupero dei costi e il costo dei finanziamenti coperti dalla garanzia deve essere inferiore al costo che sarebbe stato richiesto dal soggetto. (Art. 1.2, decreto-legge 8 aprile 2020, n. 23)

(2) h) le commissioni sono limitate al recupero dei costi e il costo dei finanziamenti coperti dalla garanzia sarà inferiore al costo che sarebbe stato richiesto dal soggetto.

En el caso de redactar las frases en voz pasiva, y si bien se prefiere el uso de la voz activa, deberá quedar claro el complemento agente.

(1) $[\ldots]$ non si possono oltrepassare i limiti stabiliti per ciascuna specie di pena, salvi i casi espressamente determinati dalla legge. (Art. 132. 2 Codice Penale Italiano)

(2) $[\ldots]$ non si possono oltrepassare i limiti stabiliti per ciascuna specie di pena, salvi i casi che la legge determina espressamente.

Se recomienda evitar las frases negativas y la doble negación en favor de frases afirmativas. 
(1) La pena della multa consiste nel pagamento allo Stato di una somma non inferiore a euro 50, né superiore a euro 50.000. (Art. 24.1. Codice Penale Italiano)

(2) La pena della multa consiste nel pagamento allo Stato di una somma tra i 50 e i 50.000 euro.

En cuanto a la relación entre frases, se recomienda elegir oraciones explícitas a las implícitas con el fin de evitar el uso del gerundio y otorgar así un contexto claro y unívoco.

(1) $[\ldots]$ garantiscono [...] c) per l'insegnamento delle lingue straniere, l'uso di strumenti compensativi che favoriscano la comunicazione verbale e che assicurino ritmi graduali di apprendimento, prevedendo anche, ove risulti utile, la possibilità dell'esonero. (Art. 5.2. Ley 170/2010 Gazzetta Ufficiale).

(2) c) per l'insegnamento delle lingue straniere, l'uso di strumenti compensativi che favoriscano la comunicazione verbale e che assicurino ritmi graduali di apprendimento, insieme alla possibilità dell'esonero ove risulti utile.

En los nexos condicionales, el elemento usado será la conjunción "se", y se escribirá, en la medida de lo posible, la prótasis en primer lugar y después la apódosis. Si en la frase introductoria se explicita la consecuencia, es necesario esclarecer la circunstancia mediante la expresión "solo se" o equivalentes.

(1) La pena è aumentata se il fatto di cui all'articolo 319 ha per oggetto il conferimento di pubblici impieghi o stipendi o pensioni o la stipulazione di contratti [...] (art. 319-bis Codice penale).

(2) Se il fatto di cui all'articolo 319 ha per oggetto il conferimento di pubblici impieghi o stipendi o pensioni o la stipulazione di contratti [...], la pena è aumentata.

Se deben evitar las oraciones carentes de significado normativo cuando no aporten una aclaración a la norma. En el siguiente ejemplo, se asiste a la redundancia lingüística y a su simplificación.

(1) Nel caso di morte di più persone, di lesioni di più persone, ovvero di morte di una o più persone e lesioni di una o più persone, si applica la pena che dovrebbe infliggersi per l'ipotesi più grave, aumentata fino al triplo, ma la pena della reclusione non può superare gli anni venti. (Art. 452-ter Codice Penale Italiano)

(2) Nel caso di morte o lesioni di una o più persone si applica la pena che dovrebbe infliggersi per l'ipotesi più grave, aumentata fino al triplo, ma la pena della reclusione non può superare gli anni venti.

Se recomienda la elección de palabras unívocas y precisas. En caso de imposibilidad, se recurrirá a términos jurídicos, técnicos o a extranjerismos. En el siguiente ejemplo, la ley recurre a la ambigüedad en la redacción para evitar precisar exactamente la cuantificación del daño, lo cual otorga a un carácter atemporal a través de la libre decisión del sentenciador. Por este motivo, se presenta imposible otorgar un correspondiente más preciso que clarifique los adjetivos significativi e misurabili. 
(1) Chiunque abusivamente cagiona una compromissione o un deterioramento significativi e misurabili (art. 452-bis, Codice Penale)

En relación con las expresiones no discriminatorias, se prefiere el uso del masculino genérico y se evitarán las expresiones que discriminen.

(1) Ostia, i commercianti contro il sindaco Raggi: «Sul virus abbandonati dal Campidoglio». (Polisano, 2020, en Il messaggero)

(2) Ostia, i commercianti contro la sindaca Raggi: «Sul virus abbandonati dal Campidoglio».

Los términos jurídicos o técnicos se usarán de manera correcta en función de sus diferentes significados, desde su uso en las leyes, hasta el dado por el derecho y la doctrina. Además, se antoja imprescindible la importancia del contexto para su interpretación y evitar la polisemia: si se recurre a términos polisémicos, se recomienda que el contexto esclarezca correctamente el significado que se quiere otorgar. En el siguiente ejemplo, se considera el término reato ('delito') como polisémico, vista la gran clasificación que subyacen en él con responsabilidades penales diferentes.

(1) l'interessato non può conseguire una nuova patente prima che siano decorsi quindici anni dalla revoca; per il reato di cui all'articolo 589-bis, quinto comma, del codice penale, [...]. (art. 1.6 b) Legge de 23 de marzo de 2016 núm. 41)

(2) l'interessato non può conseguire una nuova patente prima che siano decorsi quindici anni dalla revoca; per il reato di omicidio stradale di cui all'articolo 589-bis, quinto comma, del codice penale, $[\ldots]$.

Se recomienda usar solo el mismo término para el mismo concepto (homogeneización terminológica) y añadir definiciones si se recurre a términos que poseen significados diferentes a los habituales, tanto fuera del ámbito común como del técnico.

(1) Quando il militare morto per causa del servizio di guerra o attinente alla guerra od il civile deceduto per i fatti di guerra contemplati negli articoli 8 e 9 [...]. (Decreto del presidente della Repubblica de 23 dicembre de 1978)

(2) Quando il militare deceduto per causa del servizio di guerra o attinente alla guerra od il civile deceduto per i fatti di guerra contemplati negli articoli 8 e 9 [...].

Por último, en cuanto a neologismos y extranjerismos, se recurrirá a ellos solo si son de uso común en la lengua italiana o en el lenguaje normativo. En el caso de que el significado no sea claro, se recomienda añadir una definición.

1) e) garantire la formazione di tutte le professionalita' che entrano in contatto con la violenza di genere e lo stalking. (art 5 Decreto Legge 14 agosto 2013)

2) e) garantire la formazione di tutte le professionalita' che entrano in contatto con la violenza di genere e lo stalking (atti persecutori) 


\section{CONCLUSIONES}

El lenguaje jurídico representa un elemento arcaico en la comunicación con características aparentemente inmutables. Los debates acerca de su modernización no han producido el efecto esperado sobre las normas actuales, pues la mera búsqueda de textos legislativos en los diarios oficiales en España y en Italia sigue demostrando la tendencia al respeto de las características que lo vieron nacer. No obstante, se ha asistido a diferentes esfuerzos por reelaborar un lenguaje inteligible para una mayor comprensión de las normas, ya que los ciudadanos necesitan, por una parte, conocer con claridad sus derechos y obligaciones, y por otra, relacionarse eficazmente con las figuras jurídicas. En el caso de España, fue necesaria en 2002 la Carta de Derechos de los Ciudadanos ante la Justicia para la creación de la Comisión para la Modernización del Lenguaje Jurídico que proporcionara unas normas específicas a través del Informe del 2011. Si bien los estudios de campo que se llevaron a cabo años más tarde no tuvieron la misma repercusión, la Real Academia Española en colaboración con el Ministerio de Justicia, en el mes de junio de 2020, mostraron sus intenciones de retomar la modernización del lenguaje jurídico. En el caso italiano, en cambio, se observó ya una cierta inquietud en los años 80 que se concretó en varios documentos de exitosa publicación llevados a cabo por diferentes ministros del Dipartimento della Funzione Pubblica. Para demostrar la necesidad imperante de tales textos, a través de estas líneas se han analizado las recomendaciones tanto del Informe de la Comisión de modernización del lenguaje jurídico como del manual Regole e suggerimenti per la redazione dei testi normativi. A tal propósito, se han ofrecido algunos ejemplos inadecuados del lenguaje jurídico extraídos de la legislación junto con una propuesta de mejora a partir de las diferentes recomendaciones. Si bien se tenga constancia en ambas guías de la redacción abstrusa y ampulosa del lenguaje jurídico, que crea frases extensas y de difícil delimitación, se evidencian algunos puntos críticos:

En el caso español se desaconseja el uso de la oración pasiva, mientras que en la guía italiana solo se menciona la necesidad de aclarar el complemento agente en su uso, vista la tendencia a la pasividad de esta lengua; se resalta el uso incorrecto de la construcción $a$ seguida de verbo, propia del lenguaje jurídico español; se opone al uso de latinismos, contrariamente al italiano, dado que al ser la lengua que más influencia recibió del latín vulgar recurre a ellos con gran asiduidad, incluso en la lengua común; por último, se resalta la necesidad de usar comillas dobles en las citaciones, favoreciendo las angulares frente a las inglesas, a diferencia del italiano, quien favorece únicamente el uso de estas últimas.

En el caso italiano, en cambio, se observa una tendencia al uso del presente de indicativo, en contraste con el español jurídico, en donde rige el futuro y el subjuntivo por el carácter hipotético que otorgan; resalta el uso de expresiones no discriminatorias, las cuales no se recogen en el manual dedicado al español, y, por último, subraya la tendencia al uso de neologismos en la lengua italiana que deben evitarse en el lenguaje jurídico a menos que no estén plenamente consolidados.

Con todo, es menester destacar que la lengua la molden los hablantes, y en ocasiones, el lenguaje de las leyes no refleja la percepción lingüística de los mismos. Por ello, se antojan profundas revisiones lingüísticas en el campo legal tanto para el caso español como para el italiano que añadan un punto de reflexión adicional a lo expuesto sobre la falta de adaptación de las leyes para una mejor comprensión por parte de los ciudadanos, como destinatarios de las normas preceptivas emanadas por el Estado. 


\section{REFERENCIAS BIBLIOGRÁFICAS}

Albano, P. (2004). Appunti di comunicazione pubblica. Soveria Mannelli: Rubbettino.

Alcaraz, V. y Hughes, B. (2002). El español jurídico. Barcelona: Ariel Derecho.

Altalex. (s. f.). Codice Penale. https://www.altalex.com/documents/codici-altalex/2014/10/30/codicepenale

Bombardelli, M. (2008). "La trasparenza nella gestione dei documenti amministrativi" en F. Merloni, G. Arena, G. Corso, G. Gardini y C. Marzuoli (eds.), La trasparenza amministrativa, 385-403. Milán: Giuffrè.

Carta de derechos de los ciudadanos ante la justicia (2002). Recuperado de https://sedejudicial. justicia.es/sje/PA_WebApp_SGNTJ_NSJE/descarga/Carta $\% 20 \mathrm{de} \% 20 \mathrm{derechos} \% 20 \mathrm{de} \% 2010$ s $\% 20$ ciudadanos.pdf?idFile=a9809969-7228-4a35-97f2-b924ec38ab44

Etxebarria, M. (1997). "El lenguaje jurídico y administrativo. Propuestas para su modernización y normalización". Revista Española de Lingüistica, 27, 341-380. Recuperado de https://dialnet. unirioja.es/servlet/articulo?codigo $=41346$

Fioritto, A. (1997). Manuale di stile. Boloña: Il Mulino.

Fundación del español urgente (2007). Libro de estilo del ilustre Colegio de Abogados de Madrid. Madrid: Marcial Pons Ediciones Jurídicas y Sociales.

González Salgado, J. A. (2009). "El lenguaje jurídico del siglo XXI". THEMIS 57, 235-245. Recuperado de: https://dialnet.unirioja.es/servlet/articulo?codigo=5110481

Gotti, M. (1991). I linguaggi specialistici. Caratteristiche linguistiche e criteri pragmatici. Florencia: La Nuova Italia.

Gozzi, P. (2004). "Babele in Mitteleuropa. La traduzione della legislazione comunitaria nelle lingue dei paesi candidati" en L. Raga y M. Magris (eds.), Übersetzen in der Fachkommunikation Comunicazione specialistica e traduzione, 272-281. Berlín: Gunter Narr Verlag Tübingen.

Ministero della Funzione Pubblica (2002). Direttiva sulla semplificazione del linguaggio dei testi amministrativi. Recuperado de http://www.funzionepubblica.gov.it/sites/funzionepubblica.gov.it/ files/16872.pdf

Ministerio de Justicia (2011). Informe de la Comisión de modernización del lenguaje jurídico. Recuperado de http://www.upv.es/entidades/VRSC/info/U0711342.pdf

Ministerio de Justicia (2012). Plan Estratégico de Modernización de la Justicia 2009-2012. Recuperado de https://www.mjusticia.es/estatico/cs/mjusticia/pdf/PEModernizacion2009_2012.pdf

Ministerio para las Administraciones Públicas (1990). Manual de estilo del lenguaje administrativo. Madrid: Instituto Nacional de Administración Pública.

Montolío Durán, E. (2013). Democracia y justicia comprensible. A propuesta de clarificación del discurso jurídico en España. Linha d'Água, n. 26 (2), p. 51-69. Recuperado de https://core.ac.uk/ download/pdf/268342194.pdf

Osservatorio legislativo interregionale (2007): Regole e suggerimenti per la redazione dei testi normativi. Recuperado de https://www.consiglio.regione.fvg.it/iterleggi/drafting/drafting.pdf

Pedone, M. (2004). "Tecniche di redazione dei testi normativi e semplificazione del linguaggio amministrativo". Instrumenta, 24 (8), 988-1006. Recuperado de http://culturaprofessionale. interno.gov.it/FILES/docs/1260/instrumenta_24_07_pedone.pdf

M. Polisano, M. (30 de abril de 2020): Ostia, i commercianti contro il sindaco Raggi: «Sul virus abbandonati dal Campidoglio». Il messaggero. Consultado el 22 de junio de 2020, https://www. ilmessaggero.it/roma/news/ostia_commercianti_virus_sindaco_raggi-5201211.html

Presidenza del Consiglio dei Ministri (1994). Codice di stile delle comunicazioni scritte a uso delle pubbliche amministrazioni. Roma: Istituto Poligrafico e Zecca dello Stato. Recuperado de http:// www.francescagagliardi.it/wp-content/uploads/00-codice-di-stile-cassese-1994.pdf

Real Academia Española (2005). Diccionario panhispánico de dudas. Madrid: Santillana. 
Relinque Barraca, M. (2017). El proceso de modernización del lenguaje jurídico en el Reino Unido, los Estados Unidos y España, y su reflejo en el lenguaje utilizado por los jueces. FITISPos International Journal: Public Service Interpreting and Translation, (4), 85-101. Recuperado de https://ebuah.uah.es/dspace/handle/10017/29782

Tribunal Supremo (2016). Guía breve del prontuario del estilo para el Tribunal Supremo. Recuperado de http://campus.usal.es/ vito/DOCUMENTOS/prontuarioestiloTS.pdf

\section{NORMATIVA}

Codice penale. Regio Decreto 19 ottobre 1930, n. 1398.

Decreto BOE núm. 350, de 16 de diciembre de 1947

Decreto del Presidente della Repubblica de 23 dicembre de 1978, núm. 915. Gazzeta Ufficiale núm. 28, de 29 de enero de 1979.

Decreto-Legge núm. 93, de 14 de agosto de 2013. Gazzetta Ufficiale núm. 242 de 15/10/2013.

Decreto-ley núm. 94. Gazzetta Ufficiale, 8 de abril de 2020

JUS/3126/2003, de 30 de octubre. BOE núm. 270, de 11 de noviembre de 2003

Legge 23 de marzo de 2016, núm. 41. Gazzetta Ufficiale núm. 70 de 24/03/2016.

Ley núm 241. Gazzetta Ufficiale, 18 de agosto de 1990

Ley Orgánica 2/1989. BOE» núm. 92, de 18 de abril de 1989

Ley Orgánica PJ 6/1985. BOE» núm. 157, de 2 de julio de 1985

Real Decreto. Gaceta de Madrid núm. 260, de 17 de septiembre de 1882

Regio Decreto núm. 476, de 16 marzo 1942. Gazzetta Ufficiale, núm. 120, de 21/05/1942.

Resolución de 20 de enero de 2020. BOE núm. 263, de 5 de octubre de 2020.

Resolución de 28 de octubre de 2005. BOE» núm. 261, de 1 de noviembre de 2005.

Resolución de 7 de octubre de 2020. BOE núm. 269, de 10 de octubre de 2020.

Sentencia J. I. $n^{\circ} 9$ de Madrid P. A. 3173/2013

STC 117/2011. BOE núm. 184, de 2 de agosto de 2011 